\title{
Perineal Pain Management with Cryotherapy after Vaginal Delivery: A Randomized Clinical Trial
}

\section{Manejo da dor perineal com crioterapia no pós-parto vaginal: ensaio clínico randomizado}

\author{
Ítalo Morais ${ }^{1}$ Andréa Lemos ${ }^{2,3}$ Leila Katz ${ }^{2}$ Lorena Fernandes Rosendo de Melo ${ }^{4}$ \\ Mariano Maia Maciel ${ }^{4}$ Melania Maria Ramos de Amorim²,5
}

\footnotetext{
1 Post-Graduate Program in Maternal-Infant Health, Instituto de Medicina Integral Professor Fernando Figueira (IMIP); Department of Physical Therapy, Centro Universitário Maurício de Nassau (UNINASSAU), Recife, Pernambuco, Brazil

2 Post-Graduate Program in Maternal-Infant Health, Instituto de Medicina Integral Professor Fernando Figueira, Recife, Pernambuco, Brazil

${ }^{3}$ Department of Physical Therapy, Universidade Federal de Pernambuco (UFPE), Recife, Pernambuco, Brazil

${ }^{4}$ Cientific Initiation Program, Instituto de Medicina Integral Professor Fernando Figueira (IMIP). Undergraduate course in Medicine, Faculdade Pernambucana de Saúde (FPS), Recife, Pernambuco, Brazil ${ }^{5}$ Instituto Paraibano de Pesquisa Professor Joaquim Amorim Neto (IPESQ); Department of Medicine, Universidade Federal de Campina Grande (UFCG), Campina Grande, Paraiba, Brazil
}

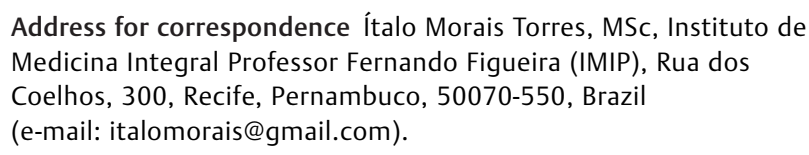

Address for correspondence Ítalo Morais Torres, MSc, Instituto de Medicina Integral Professor Fernando Figueira (IMIP), Rua dos Coelhos, 300, Recife, Pernambuco, 50070-550, Brazil (e-mail: italomorais@gmail.com).

Rev Bras Ginecol Obstet 2016;38:325-332.

received

September 3, 2014

accepted

May 17, 2016

published online

July 18,2016
Introduction Systematic reviews that evaluate the perineal cryotherapy to reduce pain in the vaginal postpartum are inconclusive.

Purpose To evaluate clinical effectiveness of cryotherapy in the management of humanized postpartum perineal pain and vaginal edema.

Methods A double-bind randomized controlled clinical trial (UTN number: U11111131-8433) was conducted in a hospital in Northeastern, Brazil. Women were included following humanized childbirth. All had vaginal deliveries of a single, full-term pregnancy with cephalic presentation. Exclusion criteria included previous perineal lesion, episiotomy during the current delivery, instrumental delivery, uterine curettage and postpartum hemorrhage. In the experimental group, an ice pack was applied six times on the perineum for 20 minutes, reducing the temperature between 10 and $15^{\circ}$ C, then 60 minutes without exposure to cold. In the non-cryotherapy, a water bag unable to reduce the temperature to this extent was used, compliance with the same application protocol of the first group. Perineal temperature was monitored at zero, 10 and 20 minutes for application in both groups. Evaluations were made immediately

- postpartum period

- natural childbirth

DOI http://dx.doi.org/ 10.1055/s-0036-1584941. ISSN 0100-7203.
Copyright $@ 2016$ by Thieme Publicações License terms

Ltda, Rio de Janeiro, Brazil 


\section{Resumo}

\author{
Palavras-chave \\ - crioterapia \\ - manejo da dor \\ - períneo \\ - período pós-parto \\ - parto normal
}

before and after the applications and 24 hours after delivery spontaneous, to determine the association between variables.

Results A total of 80 women were included in the study, 40 in each group. There was no significant difference in scores of perineal pain and edema between the groups with or without cryotherapy until 24 hours after childbirth. There was no difference between groups when accomplished repeated measures analysis over the 24 hours after delivery, considering the median perineal pain $(p=0.3)$ and edema $(p=0.9)$. Perineal cryotherapy did not influence the amount of analgesics used $(p=0.07)$ and no adverse effect was registered.

Conclusion The use of cryotherapy following normal vaginal delivery within the concept of humanized minimally interventionist childbirth had no effect on perineal pain and edema, since it was already substantially lower, nor the need for pain medicaments.

Introdução Revisões sistemáticas que avaliam a crioterapia perineal para redução da dor no pós-parto por via vaginal são inconclusivas.

Objetivo Avaliar a efetividade clínica da crioterapia para controlar a dor e o edema perineais após parto vaginal humanizado.

Métodos Ensaio clínico ( $n^{\circ}$ UTN: U1111-1131-8433) randomizado controlado duplocego, realizado em uma maternidade no Nordeste do Brasil. Incluíram-se mulheres após parto vaginal humanizado, de gestação única, cefálica, a termo, e foram excluídas aquelas com lesão perineal prévia, episiotomia no parto atual, parto instrumental e hemorragia perineal ativa. O grupo experimental foi submetido a seis aplicações de bolsa de gelo triturado na região do períneo, por 20 minutos, reduzindo a temperatura entre 10 e $15^{\circ} \mathrm{C}$, com 60 minutos entre as aplicações. O grupo sem crioterapia recebeu uma bolsa de água, que não reduzia a temperatura a esse nível, respeitando o mesmo protocolo de aplicação do primeiro grupo. A monitorização da temperatura perineal foi realizada nos minutos zero, 10 e 20 de aplicação, em ambos os grupos. Para determinar a associação entre as variáveis, foram realizadas avaliações imediatamente antes e após as aplicações e 24 horas após o parto.

Resultados Foram incluídas 80 puérperas no estudo, sendo 40 em cada grupo. Não houve diferença significativa para os escores de dor e edema perineais entre os grupos com ou sem crioterapia até 24 horas após o parto. Não houve diferença entre os grupos quando realizada análise de medidas repetidas em todas as avaliações, considerando a mediana dos escores de dor $(p=0,3)$ e edema $(p=0,9)$ perineais. A crioterapia perineal não influenciou na quantidade de analgésicos utilizados $(p=0,07)$ e nenhum efeito adverso foi registrado.

Conclusões A utilização da crioterapia após parto vaginal humanizado, minimamente intervencionista, não modifica escores de dor e edema perineais, por já serem, substancialmente, baixos, tampouco altera a necessidade de medicamentos analgésicos.

\section{Introduction}

One of the most frequent complaints reported by puerperae after vaginal deliveries is perineal pain. Prevalence studies indicate that this is one of the worst outcomes on the first postpartum day, and that it may be present in $>88 \%$ of puerperae. ${ }^{1,2} \mathrm{~A}$ report from a Chinese study suggests that one of the greatest long-term concerns is continuous pain in the perineal region after a vaginal delivery. ${ }^{3}$ Thus, many effective alternatives designed to minimize this complaint have been studied.
Some of the therapies used to provide perineal analgesia following vaginal deliveries include pharmacological and non-pharmacological interventions. In a public maternity ward in the city of São Paulo, 98.5\% of the puerperae received drugs to control pain, and the drugs most frequently used were non-steroidal anti-inflammatory agents. ${ }^{4}$

The use of non-pharmacological treatments to manage postpartum perineal pain has been investigated worldwide, because, in addition to being associated with lower risks of adverse reactions, they lower the costs associated with 
medications. ${ }^{5}$ Hence, analgesic therapy involving perineal cryotherapy is being widely researched, because it is easily accessible and inexpensive. ${ }^{6-11}$

Applying cold therapy immediately after acute injuries reduces inflammation, secondary hypoxia, the production of cellular debris, edema, hematoma development, the metabolism, spasticity, muscle spindle activity, and nerve transmissions. Moreover, it increases the release of endorphins and stimulates the repair process. ${ }^{12-15}$

Cryotherapy reduces blood flow and the metabolism within the affected region, thereby limiting edema formation. This favors the lymphatic drainage of the site, because there is less pressure in the extracellular fluid. All of these factors reduce nerve stimulation within the affected region and, therefore, pain. ${ }^{16}$

Few studies have assessed the effectiveness of cryotherapy at controlling perineal pain after vaginal deliveries and generated robust evidence. A controlled clinical trial compared a group that had ice packs applied to the perineum with a group that was not treated, and compared with the latter group, the former group reported less severe or moderate pain between 24 hours and 72 hours after childbirth. $^{17}$

A Cochrane systematic review emphasizes that using perineal cryotherapy for up to 20 minutes per application is safe and that it has no adverse effects. However, this review concludes that the effectiveness of perineal cryotherapy remains controversial, because there are no studies that have followed rigorous protocols that have controlled the degree of temperature reduction, have determined the number of times that the treatment should be applied, have determined associations with edema reductions, or have evaluated the participants' satisfaction. ${ }^{18}$

Thus, the present study aimed to evaluate the clinical effectiveness of cryotherapy for pain relief and at controlling perineal edema after vaginal deliveries.

\section{Methods}

A randomized double-blind clinical controlled study was performed that compared a group of puerperal women who underwent perineal cryotherapy with a control group that did not undergo cryotherapy. The research was performed at a low-risk maternity ward at the Instituto de Medicina Integral Professor Fernando Figueira (IMIP), which is located in the municipality of Recife, Pernambuco, Brazil. The data were collected from May 2012 to October 2012.

The StatCalc module within the Epi-Info software, version 3.5.3 (CDC, Atlanta, USA), was used to determine the sample size that was based on a literature-derived frequency of $90 \%$ for perineal pain ${ }^{1}$ during vaginal deliveries in puerperal women who had not been exposed to treatment, and a risk ratio (RR) of 0.6 for the incidence of perineal pain with cryotherapy. ${ }^{17}$ Taking into account a level of significance of $5 \%$ and a power of $80 \%$, it was necessary to recruit 60 women to uncover differences between the groups. However, foreseeing possible losses, this number was increased to 80 puerperal women who were divided equally between the cryotherapy and the control groups.

This research project was approved by the local research ethics committee (Number: 2805-12), and the women were included in the study only if they had agreed to participate and had signed a Free and Informed Consent Term. This clinical trial was registered with the Brazilian Registry of Clinical Trials (UTN number: U1111-1131-8433). There are no conflicts of interest to declare.

Women were included if they had undergone single gestations, had delivered between the thirty-seventh and forty-second weeks with cephalic fetal presentations, and had undergone vaginal deliveries. Women who underwent episiotomies, received analgesia during labor, underwent instrumental deliveries, including those with forceps or vacuums, or uterine curettages, and those who presented with active perineal hemorrhages or who had already experienced some perineal injury before delivery were excluded from the study.

The eligible participants were randomized into two groups, namely, those who underwent perineal cryotherapy and those who did not undergo perineal cryotherapy. The participants were separated into the groups using a list of random numbers that had been generated using Random Allocation Software, version 1.0. The list was drawn up by an employee who was not involved in collecting the data. One researcher determined the group to which the participants would be allocated by consulting the randomization list, and they applied the therapy. Another blinded researcher evaluated the outcomes, and the same evaluator was retained for the whole study sample.

An ice pack was applied for 20 minutes to the perineal regions of the subjects who underwent cryotherapy, which was sufficient to maintain the temperature of the midpoint of the perineal body at between $10^{\circ} \mathrm{C}$ and $15^{\circ} \mathrm{C}$, thereby reproducing the protocol recommended in the literature that achieved an analgesic effect. ${ }^{11,19}$ The first applications occurred 2 hours after the vaginal deliveries and were repeated 6 times with 60-minute intervals during which there was no exposure to cold.

A water pack at between $20^{\circ} \mathrm{C}$ and $25^{\circ} \mathrm{C}$ was applied to the perinea of the puerperae who did not undergo cryotherapy, using the same protocol as that used for the group that underwent cryotherapy in relation to timing and the numbers of applications. In this group, the water used did not have the thermal capacity to change the perineal temperature by $5^{\circ} \mathrm{C}$, which ensured that it would not have any therapeutic effects.

Latex medical gloves were used to create the ice or water packs. Before the gloves for the cryotherapy group were filled, the ice was always crushed to provide the best alignment with the perineal contours. Both types of pack were wrapped in wet surgical dressings to avoid direct contact with the perineum, to achieve greater comfort during the application, and to disguise the treatments being provided.

All of the participants had their perineal surface temperatures monitored during treatment at zero, 10, and 20 minutes, which determined the ideal reduction in 
temperature required to attain a therapeutic effect. When the temperature was not at the recommended level in the cryotherapy group, more ice was used. Studies have shown that such thermal control is essential to ensure that the temperature of the site to which the cryotherapy is applied remains at $<15^{\circ} \mathrm{C}$, and to effectively provide analgesia from 10 minutes after the therapy is applied. ${ }^{11,19}$

An Incoterm ST-600 infrared thermometer (Incoterm, São Paulo, Brazil) was used to measure the temperature, and it was positioned at $\sim 90^{\circ}$ from the midpoint of the perineum between the vaginal and anal orifices. The thermometer was calibrated during the entire data collection phase.

Perineal pain was the study's primary outcome, and perineal edema, the use of analgesic medications, and the adverse effects of cryotherapy were the study's secondary outcomes. The evaluations of pain and edema were performed immediately before and at the end of each application in each group to determine the immediate effects of therapy. These primary and secondary outcomes were evaluated again at 24 hours after delivery to ascertain the late effects of the cryotherapy.

The combined scale for assessing pain (CSAP) was used to evaluate the level of pain. The CSAP integrates the visual analog scale (VAS), faces pain scale, categorical scale, and the numerical scale, and it ranges from zero to 10 , with zero indicating a total absence of pain, and 10 indicating the most extreme pain that can be felt. ${ }^{20}$ For analytical purposes, the perineal pain was recoded as absent/mild, which corresponded to values between zero and 5, and moderate/severe, which corresponded to values between 6 and 10 .

Since a validated scale to assess perineal edema was not found in the literature, a scale was developed to measure this outcome, and it was based on an instrument that has been used to evaluate the postpartum vulvoperineal region. ${ }^{21}$ The scale used to measure perineal edema was as follows: 0: no signs of tumefaction, hyperemia, or bulging in any region of the perineum; 1 : signs of edema in the labia minora only; 2 : edema extending from the labia minora to the labia majora, including a loss of contour and/or symmetry; 3: signs of edema encompassing the labia minora, labia majora, and the vestibule; and 4: edema reaching the perineal body. For analytical purposes, the perineal edema was recoded as absent/mild, which corresponded to categories 0 and 1 , and moderate/severe, which corresponded to categories 2, 3, and 4 .

A sensitivity analysis was performed using the intentionto-treat principle for missing continuous variable data and the last observation carried forward method. ${ }^{22}$ The statistical analyses were performed using two computer programs. First, the frequency distribution tables were obtained for the categorical variables using Epi-Info, version 7.1 (CDC, Atlanta, USA), and the central tendency and the dispersion were calculated for the numerical variables. Evaluations of the associations between the independent, that is, the use of cryotherapy, and the dependent, that is, the outcomes, variables were assessed using Pearson's chi-square test of association and Fisher's exact test, as appropriate. The RRs were calculated, and the 95\% confidence intervals were determined. Repeated measures analysis of variance (ANOVA) was performed using the MedCalc software, version 12.6.0.1 (MedCalc, Oostende, Belgium), to compare the groups' median pain and edema scores at the different evaluation times.

\section{Results}

During this study, 288 deliveries were recorded in the lowrisk obstetric care ward at the IMIP. Eighty-eight women were approached to participate in this study, and, of these, 84 were eligible and 4 were not eligible. Among the eligible candidates, 4 did not agree to participate; therefore, 80 women who signed the Free and Informed Consent Term were included in the study.

Two losses were recorded during data collection. Of these, one patient developed eclampsia and had to be referred to the intensive care unit, and the other patient wished to exit the study. Both of these patients had been assigned to the cryotherapy group, and their data were analyzed up until the time they were included in the study. The baseline characteristics of the women and their newborns were similar in both groups ( $\mathbf{- T a b l e ~} \mathbf{1}$ ).

There was no significant difference between the groups in relation to perineal pain after vaginal delivery. The assessments performed before and after each of the 6 applications, and the evaluations at 24 hours after delivery showed that the moderate/severe pain scores were similar in both study groups. Moderate/severe pain was absent from at least one of the groups during all of the evaluations, except for the first measurement, which impeded the estimation of the RRs between the treatments.

Immediately before the first ice pack or water pack was applied, $10.0 \%$ of the participants in the cryotherapy group and $2.5 \%$ of the participants in the control group had moderate/severe perineal pain (RR: 4.0), a difference that was not significant $(p=0.3)$. A repeated measures ANOVA did not determine a significant difference between the groups in relation to the median scores for pain over 24 hours $(p=0.3)$

\section{(-Fig. 1).}

There were no significant differences between the groups in relation to the perineal edema scores, and moderate/severe edema displayed similar decreasing trends over time, regardless of the therapy applied. At 24 hours after delivery, there was a greater difference between the groups with respect to moderate/severe perineal edema, with $7.9 \%$ of the subjects in the cryotherapy group and $22.5 \%$ of the subjects in the control group reporting moderate/severe perineal edema (RR: 0.35 ), a difference that was not statistically significant $(p=0.07)$. A repeated measures ANOVA did not determine a difference between the groups in relation to the median scores for perineal edema $(p=0.9)$ (-Fig. 2).

There was no significant difference between the groups with respect to the need for drug therapy to control perineal pain (RR $0.07 ; p=0.7$ ). None of the patients had any adverse reactions to the cryotherapy. No allergies to the latex gloves filled with water or ice or urticaria were recorded. 
Table 1 Baseline characteristics of the mothers and their neonates within the groups exposed or not exposed to cryotherapy to control perineal pain following vaginal deliveries

\begin{tabular}{|c|c|c|c|}
\hline Baseline characteristic & $\begin{array}{l}\text { With cryotherapy } \\
(n=40)\end{array}$ & $\begin{array}{l}\text { Without cryotherapy } \\
(n=40)\end{array}$ & $p$ \\
\hline Age (years) & & & $0.9^{*}$ \\
\hline Range & $13-36$ & $12-37$ & \\
\hline Mean (SD) & $22.5(5.4)$ & $22.7(5.9)$ & \\
\hline BMI $\left(\mathrm{kg} / \mathrm{m}^{2}\right)$ & & & $0.6^{*}$ \\
\hline Range & $20.81-39.0$ & $19.1-35.3$ & \\
\hline Mean (SD) & $27.6(3.9)$ & $27.2(3.9)$ & \\
\hline Gestational age (weeks) & & & $0.8^{*}$ \\
\hline Range & $38.0-40.0$ & $38.0-40.0$ & \\
\hline Mean (SD) & $39.0(1.2)$ & $39.00(1.4)$ & \\
\hline Parity & & & $0.5^{*}$ \\
\hline Range & $0-1$ & $0-1$ & \\
\hline Mean (SD) & $0(1.4)$ & $0(0.9)$ & \\
\hline Birth weight $(g)$ & & & $0.4^{*}$ \\
\hline Range & $2380.0-4270.0$ & $2460.0-4580.0$ & \\
\hline Mean (SD) & $3241.25(396.89)$ & $3314.0(400.59)$ & \\
\hline Head circumference $(\mathrm{cm})$ & & & $0.6^{*}$ \\
\hline Range & $32.0-39.0$ & $31.0-39.0$ & \\
\hline Mean (SD) & $34.7(1.8)$ & $34.5(1.5)$ & \\
\hline Spontaneous laceration n (\%) & $28(70.0)$ & $35(87.5)$ & $0.06^{* *}$ \\
\hline
\end{tabular}

Abbreviations: BMI, body mass index; cm, centimeters; n, number; SD, standard deviation.

"t test;

${ }^{* *}$ Pearson's chi-square test.

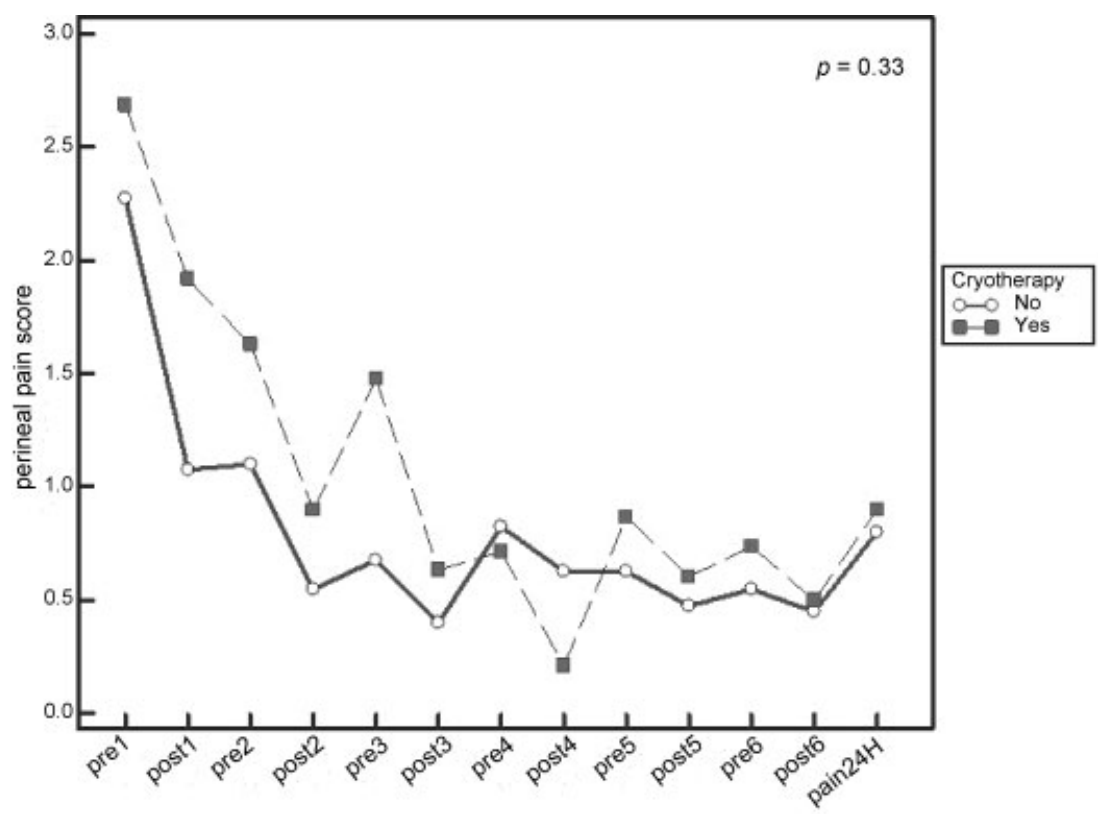

Fig. 1 Repeated measures analysis of variance of the pain scores before and after the application of the cryotherapy or the placebo, and 24 hours after vaginal delivery. Abbreviations: pre, pain before the application; post, pain after the application. 


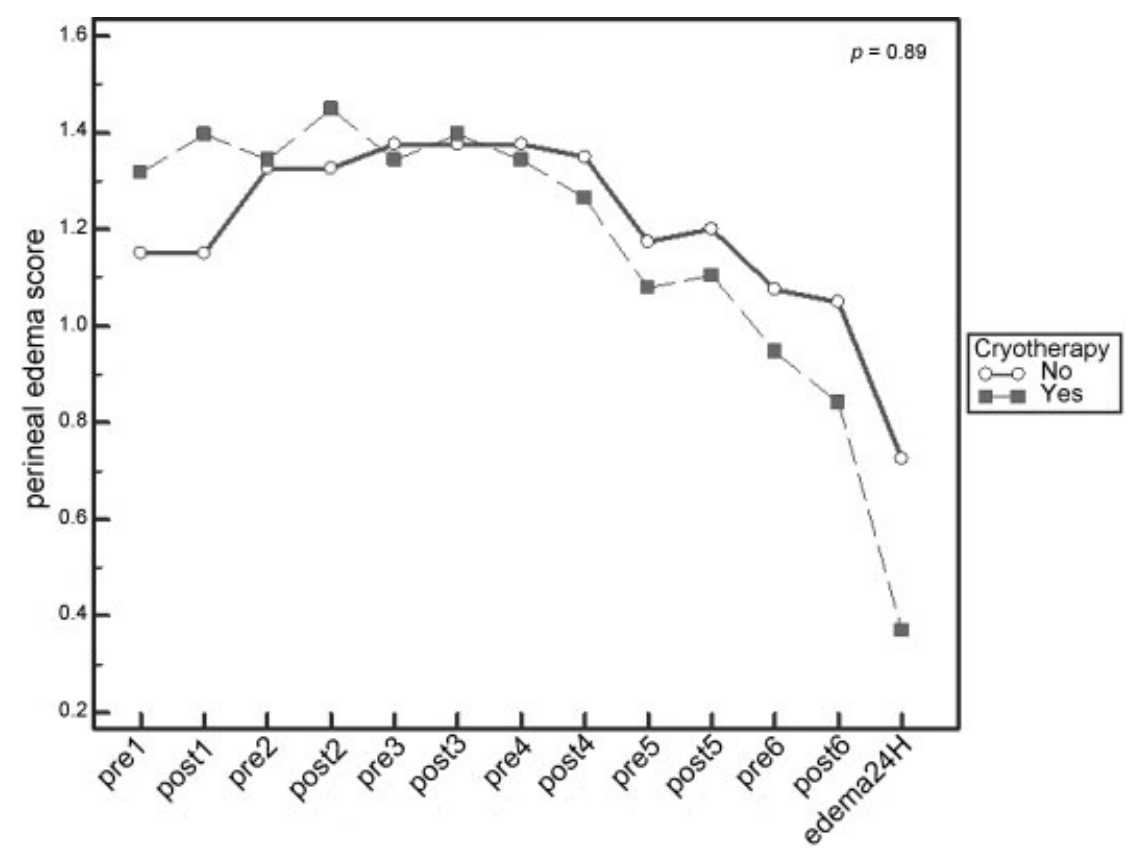

Fig. 2 Repeated measures analysis of variance of the edema scores before and after the application of the cryotherapy or the placebo, and 24 hours after vaginal delivery. Abbreviations: pre, edema before the application; post, edema after the application.

According to the temperature monitoring, all patients underwent cryotherapy remained with reduced temperature between 10 and $15^{\circ} \mathrm{C}$ during the 10th and 20th minute application of ice. Meanwhile, the group of patients without cryotherapy did not reduce perineal temperature less than $5^{\circ} \mathrm{C}$, comparing the initial temperature to the procedure.

\section{Discussion}

The results from this study suggest that while using cryotherapy after vaginal deliveries complies with a minimal intervention model of care, it does not modify the levels of perineal pain and edema, neither does it alter the use of analgesic medications. However, it is important to note that the initial pain and edema scores were extremely low, and they did not change significantly during the courses of either of the applications, regardless of whether or not cryotherapy was used.

The results from this study concur with the findings from a clinical trial that evaluated the effectiveness of perineal cryotherapy in 120 women and showed that there were no significant differences between the therapeutic applications in relation to pain intensity. ${ }^{23}$ However, the present study's results differ from those from the aforementioned study, because the group that underwent cryotherapy reported less moderate/severe pain after 24-72 hours compared with the group that did not receive any therapy. Notably, the study included women who had undergone instrumental deliveries and episiotomies.

A quasi-experimental study ${ }^{24}$ applied perineal cryotherapy once only for 20 minutes to puerperal women after vaginal deliveries, and the findings showed a significant reduction in pain immediately after therapy (RR: 5.4; $p<0.0005)$. However, all of the patients in this study had already presented with perineal pain that was $>3$ on the VAS scale, and the sample included women with intact perinea, lacerations, and those who had undergone episiotomies.

The divergence between the other studies' results and those from the present study can be explained in the context of the different populations studied. Procedures that expose the perineal tissue to greater risks of trauma are determining factors for higher pain scores immediately after delivery. ${ }^{5,25-28}$ A study performed in São Paulo demonstrated that an episiotomy and maternal age were the only independent predictive factors for perineal pain after a vaginal delivery. ${ }^{29}$ Another study also warns that this practice can increase the risk of dyspareunia after delivery. ${ }^{30}$ In the maternity ward from which this study's data were collected, deliveries by low-risk women are assisted by obstetric nurses who follow a minimal intervention model of care, which enables the deliveries to occur spontaneously and physiologically.

A report from a study of 143 Nigerian puerperae pointed out that the women who underwent episiotomies were characterized by a 2-fold higher risk of perineal pain compared with the women who did not experience trauma in this region (RR: 2.4). The frequency of pain at 24 hours after delivery in the women with intact perinea was $38.3 \%$, but $86.8 \%$ of the patients who underwent episiotomies experienced pain. ${ }^{31}$ Therefore, the data from the aforementioned Nigerian study and those from the present study concur with 
the findings from a Cochrane review ${ }^{32}$ that demonstrated that perineal pain was lower when routine episiotomies were not performed. A prospective investigation ${ }^{33}$ of 243 women also found a positive correlation between this procedure and urinary incontinence.

The data used to calculate the study's sample size for the statistical analyses were based on data that were available in the literature at the time when this study was planned, which reported that $90 \%$ of puerperal women described moderate/severe perineal pain after a vaginal delivery. ${ }^{1}$ However, the frequency determined in the current study was much lower, and only $6.3 \%$ of the subjects reported moderate/severe perineal pain at 2 hours after a vaginal delivery, which was the time when the evaluations and treatment began.

The perineal edema data from this study concur with a systematic review. ${ }^{18}$ Neither study demonstrated statistically significant differences for this outcome either in relation to evaluations of immediate cryotherapy or in relation to late assessments that occurred at 24 hours after delivery. Notably, the findings from a recent study suggest that local cooling therapy that is performed excessively and in an uncontrolled manner may worsen cases of puerperal vulvar edema and hematoma. ${ }^{34}$

We conclude that humanized delivery seems to be an effective protection strategy against perineal pain and edema, and that women whose deliveries were assisted using this model did not require cryotherapy to control these outcomes.

No studies were found that had investigated perineal cryotherapy and its association with the use of analgesic medications. In this study, the need for these medications was not significantly reduced when perineal cooling therapy was applied. This finding is not unexpected given that the perineal pain scores always remained low.

Importantly, a systematic review cites the lack of perineal temperature monitoring before, during, and at the end of therapy as a shortcoming of the studies published to date, to guarantee that the thermal reduction was sufficient to obtain some therapeutic effect ${ }^{18}$. This study measured the temperatures at zero, 10 , and 20 minutes to determine the temperature required to obtain an analgesic effect. ${ }^{11,19}$ Nevertheless, no changes in the perineal pain or edema scores were observed, despite following the recommendations regarding the temperature, and the timing and the form of the application.

No adverse effects were recorded during this study when perineal cryotherapy was applied; therefore, the results from a previously published study are corroborated, ${ }^{18}$ and this is a low-cost therapeutic alternative that does not present risks to or harm the health of puerperae.

The strength of this study is associated with it being the first clinical trial to apply 6 ice pack treatments for 20 minutes each to the perineal region of parturients. In addition, the temperature was rigorously monitored during these applications to ensure that the reduction in temperature was sufficiently therapeutic.
Only women who were assisted in "humanized" manner and that involved the minimum possible amount of vaginal manipulation during labor and childbirth were studied, and this represents a study limitation. However, this is the current standard of care for low-risk deliveries at the institution, and it would be unethical to manage these women in any other way for research purposes, because the delivery care model that would involve unnecessary interventions has already been proven to be harmful. ${ }^{35}$

Therefore, cryotherapy was not effective at controlling pain and perineal edema following vaginal deliveries that involved natural, humanized, and minimally interventional approaches, because the initial pain and perineal edema scores were extremely low. Furthermore, cryotherapy did not influence the quantities of analgesic medications used.

\section{Acknowledgments}

The authors would like to thank the IMIP and the obstetric team of that institution, the Instituto Paraibano de Pesquisa Prof. Joaquim Amorim Neto (IPESQ), for the immeasurable scientific methodological and biostatistics support, and the Fundação de Amparo à Ciência e Tecnologia do Estado de Pernambuco (Facepe) for fostering this research. The authors would also like to thank FACEPE for financial support and the Brazilian Registry of Clinical Trials (ReBEC): (UTN) U1111-1131-8433.

\section{References}

1 East CE, Sherburn M, Nagle C, Said J, Forster D. Perineal pain following childbirth: prevalence, effects on postnatal recovery and analgesia usage. Midwifery 2012;28(1):93-97

2 Persico G, Vergani P, Cestaro C, Grandolfo M, Nespoli A. Assessment of postpartum perineal pain after vaginal delivery: prevalence, severity and determinants. A prospective observational study. Minerva Ginecol 2013;65(6):669-678

3 Li WY, Liabsuetrakul T, Stray-Pedersen B. Effect of mode of delivery on perceived risks of maternal health outcomes among expectant parents: a cohort study in Beijing, China. BMC Pregnancy Childbirth 2014;14:12

4 Hasegawa J, Leventhal LC. Pharmacological and non pharmacological treatment for relief of perineal pain after vaginal delivery. Einstein (São Paulo) 2009;7(2):194-200

5 Pitangui ACR, Sousa L, Ferreira CHJ, Araujo RC, Nakano AMS. Análise da prescrição de medidas terapêuticas para o alívio da dor em puérperas pós-episiotomia. Rev Bras Fisioter. 2007;11 (Suppl):80

6 Lu YY, Su ML, Gau ML, Lin KC, Au HK. The efficacy of cold-gel packing for relieving episiotomy pain - a quasi-randomised control trial. Contemp Nurse 2015;50(1):26-35

7 Cameron H. Midwives benefit from good postnatal care, too. Pract Midwife 2014;17(7):14-16

8 Byrom A. Perineal pain in focus: reviewing topical anaesthetic treatments. Pract Midwife 2015;18(7):24, 26-27

9 Chiarelli P, Cockburn J. Postpartum perineal management and best practice. Aust Coll Midwives Inc J 1999;12(1):14-18

10 Bavaresco GZ, Souza RSO, Almeica B, Sabatino JH, Dias M. The physiotherapist as a professional to assist pregnant women. Cien Saude Colet 2011;16(7):3259-3266 
11 Francisco AA, de Oliveira SM, Leventhal LC, de Bosco CS. Cryotherapy after childbirth: the length of application and changes in perineal temperature. Rev Esc Enferm USP 2013;47(3):555-561

12 Carvalho GA, Chierichetti HSL. Avaliação da sensibilidade cutânea palmar nas aplicações de crioterapia por bolsa de gelo e bolsa de gel. Rev Bras Ciênc Mov. 2006;14(1):23-30

13 Chesterton LS, Foster NE, Ross L. Skin temperature response to cryotherapy. Arch Phys Med Rehabil 2002;83(4):543-549

14 Brancaccio N, Klein AA, Böettche GA, et al. Análise de lesão muscular em ratos treinados e sedentários submetidos a crioterapia. Fisioter Mov 2005;18(1):59-65

15 Pestre CM, Bastos FN, Netto Júnior J, Vanderlei LCM, Hoshi RA. Métodos de recuperação pós-exercício: uma revisão sistemática. Rev Bras Med Esporte. 2009;15(2):138-144

16 Swenson C, Swärd L, Karlsson J. Cryotherapy in sports medicine. Scand J Med Sci Sports 1996;6(4):193-200

17 Steen M, Cooper K, Marchant P, Griffiths-Jones M, Walker J. A randomised controlled trial to compare the effectiveness of icepacks and Epifoam with cooling maternity gel pads at alleviating postnatal perineal trauma. Midwifery 2000;16(1):48-55

18 East CE, Begg L, Henshall NE, Marchant PR, Wallace K. Local cooling for relieving pain from perineal trauma sustained during childbirth. Cochrane Database Syst Rev 2012;5(5):CD006304

19 Mac Auley DC. Ice therapy: how good is the evidence? Int J Sports Med 2001;22(5):379-384

20 Chapman CR, Syrjala KL. Measurement of pain. In: Bonica JJ, editor. The management of pain. 2nd ed. Philadelphia: Lea \& Febiger; 1990. p. 580-94.

21 Riesco MLG, de Oliveira SM. Postnatal perineal edema assessment: agreement among observers. Rev Gaucha Enferm 2007; 28(4):465-472

22 Marston L, Sedgwick P. Randomised controlled trials: missing data. BMJ 2014;349:g4656

23 Steen M. A randomised controlled trial to evaluate the effectiveness of localised cooling treatments in alleviating perineal trauma: the APT study. Midwifery Dig. 2002;12(3):373-376
24 de Souza Bosco Paiva C, Junqueira Vasconcellos de Oliveira SM, Amorim Francisco A, da Silva RL, de Paula Batista Mendes E, Steen M. Length of perineal pain relief after ice pack application: A quasi-experimental study. Women Birth 2016;29(2):117-122

25 Petrocnik P, Marshall J. Hands-on or hands-poised: what does the evidence say? Pract Midwife 2015;18(7):10-12

26 Dresang LT, Yonke N. Management of spontaneous vaginal delivery. Am Fam Physician 2015;92(3):202-208

27 Macarthur AJ, Macarthur C. Incidence, severity, and determinants of perineal pain after vaginal delivery: a prospective cohort study. Am J Obstet Gynecol 2004;191(4):1199-1204

28 Pitangui ACR, Araújo RC, Bezerra MJS, Ribeiro CO, Nakano AMS. Low and high-frequency TENS in post-episiotomy pain relief: a randomized, double-blind clinical trial. Braz J Phys Ther 2014; 18(1):72-78

29 Amorim Francisco A, Junqueira Vasconcellos de Oliveira SM, Barbosa da Silva FM, Bick D, Gonzalez Riesco ML. Women's experiences of perineal pain during the immediate postnatal period: a cross-sectional study in Brazil. Midwifery 2011;27(6): e254-e259

30 Turmo M, Echevarria M, Rubio P, Almeida C. Development of chronic pain after episiotomy. Rev Esp Anestesiol Reanim 2015; 62(8):436-442

31 Imarengiaye $\mathrm{CO}$, Andet ABA. Postpartum perineal pain among Nigerian women. West Afr J Med 2008;27(3):148-151

32 Carroli G, Belizan J. Episiotomy for vaginal birth. Cochrane Database Syst Rev 2000;(2):CD000081

33 Chang SR, Chen KH, Lin HH, Chao YMY, Lai YH. Comparison of the effects of episiotomy and no episiotomy on pain, urinary incontinence, and sexual function 3 months postpartum: a prospective follow-up study. Int J Nurs Stud 2011;48(4):409-418

34 Hubb AJ, Orr KL, Stockdale CK. Puerperal vulvar edema and hematoma complicated by overuse of cold therapy-a report of two cases. J Low Genit Tract Dis 2015;19(2):e28-e30

35 World Health Organization. Care in normal birth: a practical guide. Geneva: WHO; 1996 